\title{
CONSUMO SUSTENTÁVEL NA BASE DA PIRÂMIDE: DEFININDO PAPÉIS E OBRIGAÇÕES PARA A EFETIVAÇÃO DO DESENVOLVIMENTO SUSTENTÁVEL
}

\author{
Minelle Enéas Silva \\ Mestre em Administração Universidade Federal de Pernambuco - UFPE \\ minele.adm@gmail.com
}

\begin{abstract}
Débora Prazeres Balbino
Mestranda em Administração da Universidade Federal de Pernambuco - PROPAD/UFPE deboraprazeresb@hotmail.com
\end{abstract}

\section{Carla Pasa Gómez}

Doutora em Engenharia de Produção Universidade Federal de Santa Catarina - UFSC Professora da Universidade Federal de Pernambuco - UFPE

\section{RESUMO}

A necessidade de mudança na forma de desenvolvimento, de uma visão individualista para uma mais coletiva, favorece o desenvolvimento sustentável, que envolve a harmonização das dimensões econômicas, sociais ou ambientais. Concomitante a essa necessidade de mudança, faz-se necessário modificar os padrões de consumo até então praticados, haja vista o atual consumismo. O surgimento do consumo sustentável indica uma melhor visualização sobre as questões culturais de consumo apregoadas, assim como para a do desenvolvimento sustentável, em que os atores sociais (Governo, Empresa e Sociedade) devem interagir para que se consiga redirecionar as práticas atuais, pela corresponsabilidade que possuem. A prática sustentável do consumo pode ser visualizada nos diferentes tipos de economia (Tukker et al., 2008), cada uma merecendo um olhar diferenciado para a efetivação do consumo sustentável. Optou-se por estudar a base da pirâmide, tendo em vista seu potencial crescimento a curto prazo, ao englobar as faixas de renda C, D e E, o que representa a maioria absoluta da população e que deve receber um maior atenção em várias nações. Com base nessas considerações, o objetivo deste trabalho é compreender como o consumo sustentável pode ser efetivado na base da pirâmide, considerando que existem as influências mútuas dos atores sociais nesse sentido. Para tanto, realizou-se uma discussão teórica com o intuito de identificar ações a serem realizadas para que esse novo paradigma de consumo possa emergir nessa classe econômica.

Palavras-chave: Base da pirâmide; Consumo sustentável; Desenvolvimento sustentável.

\section{SUSTAINABLE CONSUMPTION IN THE BASE OF THE PYRAMID: DEFINING ROLES AND DUTIES OF EFFECTIVE FOR SUSTAINABLE DEVELOPMENT}

\begin{abstract}
There is a need for change in the development of an individualistic vision for a more collective responsibility and sustainability. There is sustainable development involving the harmonization of the dimensions: economic, social or environmental. To contribute to this need for change it is necessary to modify current consumption patterns practiced. The emergence of sustainable consumption indicates a better view on the issues regarding cultural consumption as well as for sustainable development in which social actors (government, business and society) must interact so that they can redirect current practices which is a responsibility they have. The practice of sustainable consumption can be viewed in different types of economy (Tukker et al., 2008) each meriting a different look for the realization of sustainable consumption. We chose to study the base of the pyramid, with a view to its potential growth in the short term to encompass income groups $\mathrm{C}, \mathrm{D}$ and $\mathrm{E}$, which represents the majority of the population and should receive greater attention in various nations. From these considerations, the objective of this study is to understand how sustainable consumption can be realized at the base of the pyramid, whereas there are the mutual influences of social actors in this regard. A theoretical discussion was carried out in order to identify actions to be performed for this new paradigm of consumption that may advance that economic class.
\end{abstract}

Keywords: Sustainable Development; Sustainable Consumption; Base of the Pyramid. 


\section{INTRODUÇÃO}

Ao longo dos anos, torna-se cada vez mais perceptível as consequências da atividade humana no meio, no que diz respeito a sua ação indiscriminada. Tais implicações são decorrentes do caráter individualista apregoado pelo pensamento capitalista até então praticado, que apregoa que a satisfação das "necessidades" humanas deve ser alcançada a qualquer custo, sem a preocupação com os possíveis efeitos dessa postura em âmbito mundial. Nesse contexto de abundância de recursos, por exemplo, o reflexo do consumo insaciável - resultado dessa visão individual - demonstra a urgência necessária da mudança de modelo de desenvolvimento a ser utilizado.

A mudança de paradigma desenvolvimentista relaciona-se com a modificação na cultura social, nas práticas de consumo da população, na forma de atuação das organizações (públicas e privadas), de maneira tal que são necessárias ações de longo prazo. Este fato é corroborado por Schumacher (2001) quando afirma que o problema deve ser entendido em sua totalidade, buscando reconhecer e desenvolver um novo estilo de vida, com novos métodos de produção e novos padrões de consumo.

Para Buarque (2008, p. 70) “[...] essa transição de um estilo insustentável para um sustentável deve, enfrentar e redesenhar a rigidez e as restrições estruturais, que demandam tempo e iniciativas transformadoras da base da organização da sociedade e da economia". Assim sendo, ações devem ser postas em prática, de maneira tal que a mudança na forma de desenvolvimento seja mais bem usufruída por toda a sociedade.

Nesse sentido, o desenvolvimento sustentável surge como a alternativa necessária, na medida em que defende a busca por uma coletividade. Sua ideia apresentada na literatura, de forma sucinta, está relacionada com a satisfação das necessidades das gerações atuais e futuras, sem que haja comprometimento da continuidade humana do planeta, por meio da harmonização entre as dimensões fundamentais: social, econômico e ambiental (Sachs, 2007).

Para que haja o alcance do desenvolvimento sustentável, existe a necessidade de realização de práticas que envolvem um papel mais ativo do governo, uma responsabilidade socioambiental das empresas, bem como uma maior consciência individual ao modificar suas atitudes enquanto integrante da sociedade. Essas práticas, além de atender aos requisitos do desenvolvimento sustentável, levam ao consumo sustentável (Pnuma, 2001), que também indica a necessidade de interação entre os atores para sua efetivação.

Vale ressaltar a falta de consenso na literatura em relação ao conceito de consumo sustentável, que, muitas vezes, é confundido com o conceito de consumo consciente ou responsável que trabalha a ideia de ação individual. Desse modo, compreende-se o consumo sustentável como essa atividade complexa efetivada pela interação entre os atores sociais supracitados. Nesse contexto, ele pode ser identificado nas várias áreas e setores da economia, e, segundo Tukker et al. (2008), varia de acordo com a classe econômica.

Diante dessa consideração, ao entender o mercado em que muitas organizações futuramente poderão se direcionar, optou-se por estudar a base da pirâmide. Prahalad (2006) afirma que a base da pirâmide deve ser incluída na sociedade em razão do crescente estímulo ao consumo que esse segmento da população tem recebido para que assim, a questão social seja minimizada. Isso, no entanto, não é justificável, na medida em que não é apenas pelo consumo que se insere um determinado segmento da população na sociedade, mas também pelo incentivo educacional e pela consciência de sua cidadania. Nesse sentido, ao considerar a atual situação quanto as questões ambientais, como será o mundo com o alto consumo de cerca de 4 bilhões de pessoas?

Nessa perspectiva, o consumo sustentável surge como alternativa, visto que seus princípios envolvem não apenas o incentivo ao consumo, como também uma preocupação com os aspectos da coletividade, a luz do desenvolvimento sustentável. Faz-se necessário, então, o desenvolvimento de 
uma conscientização nessa população, uma atuação mais ativa das instituições governamentais, bem como uma prática pró-ativa por parte das organizações, em buscar alternativas na prestação de produtos e serviços visando atuar junto a essa faixa da população, todavia preocupada com a redução dos impactos possivelmente causados.

Com o intuito de identificar essas possíveis relações até então verificadas e na busca pela identificação de ações na nova prática do modelo desenvolvimentista, este estudo tem como objetivo compreender como o consumo sustentável pode ser efetivado na base da pirâmide, considerando que existem as influências mútuas dos atores sociais nesse sentido. Assim, torna-se relevante reconhecer e inter-relacionar os constructos envolvidos com o pressuposto, no sentido de gerar um melhor entendimento da proposta abordada.

\section{REFERENCIAL TEÓRICO}

\subsection{Desenvolvimento sustentável}

Cada vez mais ficam evidenciados os reflexos das ações humanas sobre o meio, que ocorrem em âmbito social, ambiental e econômico, como as responsáveis pelos impactos percebidos atualmente, como as mudanças climáticas, as crises econômicas, bem como pelos abalos na sociedade. Essa situação indica a existência de uma miopia na visualização das questões globais, uma vez que o individualismo - consequência do modelo de desenvolvimento vigente - é a causa para essa conjuntura.

A modificação no paradigma de desenvolvimento até então praticado, demonstra ser a alternativa necessária para a permanência humana no planeta. Nesse sentido, o desenvolvimento sustentável surge como a opção mais favorável a emergir como fator de referência para nortear a dinâmica de crescimento e desenvolvimento que a estrutura econômica venha a utilizar, na medida em que se utiliza de preceitos que envolvem a articulação e o envolvimento por parte da coletividade.

O desenvolvimento sustentável pode ser entendido, em se considerando o conceito mais completo diante da evolutiva discussão quanto a essa temática - encontrado no Relatório de Brundtland, como "[...] um processo de mudança em que a exploração dos recursos, a direção dos investimentos, a orientação do desenvolvimento tecnológico e a mudança institucional estão todos em harmonia" para que as necessidades humanas possam ser satisfeitas atualmente e no futuro (Wced, 1987, n.p.).

De fato, o direcionamento das atividades para uma nova forma de prática organizacional necessita de uma "[...] mudança no pensamento mecanicista para o sistêmico, e de um sistema de valores baseado na dominação para um sistema baseado na parceria" (Casagrande Jr, 2003, p.3), indicando que o novo modelo alternativo a ser praticado, serve como subsídio para as ações organizacionais ao verificar o surgimento de uma perspectiva pautada na harmonização de três critérios fundamentais, quais sejam: equidade social, eficiência econômica e equilíbrio ambiental.

Ao longo das últimas décadas, intensificaram-se as discussões sobre como modificar essa tendência negativa que o mundo está se direcionando. Desta forma, pode-se levantar questionamentos sobre a melhor maneira de se alcançar a harmonia entre esses critérios fundamentais do desenvolvimento sustentável: Quais são, realmente, os responsáveis pela atual situação mundial? Numa perspectiva de mudança dessa situação, será que a responsabilidade deve ser direcionada apenas aos gestores públicos? Será que as organizações - empresas - são as principais responsáveis? Ou será que a sociedade, por meio de cada indivíduo ou organização civil, possui papel fundamental nesse processo de reestruturação rumo a um desenvolvimento sustentável mundial?

Apesar de se apresentar como uma questão ampla em que, normalmente, se direciona a responsabilidade de seu alcance ao Estado, é notável a necessidade de que a sociedade seja envolvida, focada em harmonizar as dimensões básicas do desenvolvimento sustentável, para que se

Revista de Gestão Social e Ambiental - RGSA, São Paulo, v. 5, n. 2, p.18-33, mai./ago. 2011. 
possa usufruir os recursos necessários da melhor maneira possível para a continuidade tanto das gerações atuais quanto das futuras, no atendimento de suas necessidades. Tal fato é citado por Buarque (2008) como a solidariedade intrageracional e intergeracional, respectivamente.

Nesta perspectiva, na busca pela manutenção dessa solidariedade, fato essencial para o desenvolvimento sustentável, percebe-se que além do Estado, cada empresa, organização do terceiro setor e indivíduo - sociedade - deve tornar-se consciente de seu papel na busca pelo desenvolvimento sustentável, uma vez que a mudança na forma de atuação posta em prática é o ponto de partida inicial para que se consiga atingir um desenvolvimento endógeno, autossuficiente, orientado para as necessidades, em harmonia com a natureza e aberto às mudanças institucionais (Sachs, 2008).

O Estado, pelas atribuições que lhe são concedidas, pode direcionar seus esforços em diferentes vertentes para auxiliar no alcance do desenvolvimento sustentável. Neste aspecto, é possível afirmar que o papel do governo é de regular e fiscalizar as atividades gerais que estejam desviadas desse objetivo, bem como financiar e fomentar o surgimento de alternativas capazes de sustentar a ação humana quanto ao meio ambiente, visando melhor organizar a sociedade. Tal aspecto envolve um maior empenho público, já que este deve ter a percepção de que suas ações podem interferir diretamente nas práticas sociais a curto, médio e longo prazo.

Outro ator social importante para o alcance do desenvolvimento sustentável pode ser reconhecido como organizações com finalidades lucrativas. A sua atuação está condicionada à busca pela harmonização no caráter de atuação e na abrangência na realização de suas atividades (Borger, 2006), fato este que pode ser efetivado pela equivalência das dimensões básicas do desenvolvimento sustentável ao conceito de sustentabilidade em organizações (Barbieri \& Cajazeira, 2009). Práticas mais coletivas demonstram o caráter socialmente responsável de uma empresa junto à população local.

O terceiro setor, pelo seu papel contributivo na solução de problemas sociais e em prol do bem comum, também pode ser considerado um dos atores sociais mais significativos na mobilização da sociedade para as questões de desenvolvimento sustentável. Portanto, a sustentabilidade de suas ações também está condicionada a essa harmonização das dimensões da sustentabilidade, adaptada ao caráter não lucrativo do setor. Entendendo-o como movimento social por distintas causas, o posicionamento das organizações no setor auxiliando o desenvolvimento sustentável, de maneira duradoura, pode ocorrer por suas atividades previamente estabelecidas e desenvolvidas com um caráter de continuidade.

Como outro ator social, pertencente à sociedade, o indivíduo, em sua singularidade, possui papel de importância na busca pelo desenvolvimento sustentável, por possuir a capacidade de escolha e tomada de decisão quanto ao que irá consumir, podendo definir, desse modo, a criação de padrões de consumo em qualquer setor econômico. Para Gomes (2007), a atuação do consumidor no mercado pode ter reflexos positivos ou negativos sobre a economia, o meio ambiente e o comportamento das empresas. Sendo que ele, corresponsável na busca pela mudança no modelo de paradigma vigente, começa a se portar como consumidor consciente, politizado e preocupado com as questões coletivas, o que torna cada vez mais próxima a efetivação dessa mudança.

Diante dessas considerações, percebe-se que a complexidade existente entre as inter-relações criadas pelos atores sociais supracitados, sugere a necessidade de uma visualização holística quanto à temática, ao entender que a mudança no modelo econômico praticado, que até então instiga o individualismo, deve direcionar-se para a busca por questões mais coletivas, que tenham impactos positivos para toda a sociedade. Essa modificação envolve também as questões pertinentes às práticas de consumo, que podem começar a reduzir seu alto impacto sobre o meio ambiente. Nesse sentido, o consumo sustentável pode ser percebido como a alternativa de consumo que indica uma melhoria na produção e no consumo dos produtos/serviços, tendo em vista seu caráter sistêmico em relação ao desenvolvimento sustentável. 


\subsection{Consumo Sustentável}

Considerada uma atividade inerente a existência e a sobrevivência humana compartilhada com todos os outros organismos vivos, a prática do consumo acompanha o ser humano em todos os momentos, direta ou indiretamente, ratificando ser indissociável viver sem consumir. Para que haja seu melhor entendimento, o consumo pode ser considerado, basicamente, uma característica e uma ocupação dos seres humanos, enquanto indivíduos (Baudrillard, 2007, Bauman, 2008).

A ideia do consumo, mais especificamente dos bens de consumo, possui uma significação que supera seu caráter utilitário e seu valor comercial, para assumir características inerentes ao aspecto cultural de uma sociedade, denominando-se cultura de consumo, com pretensões e alcances globais (Slater, 2002, Mccracken, 2003). Para Bauman (2008), existe um espaço entre a produção e o consumo, que, sendo estes autônomos, pode ser regulado, padronizado e operado por instituições mutuamente independentes.

Nessa perspectiva, para Slater (2002, p.17), “[...] o consumo é sempre em todo lugar um processo cultural". Desse modo, ainda segundo o autor, a cultura de consumo vai além da reprodução da vida cotidiana, atingindo, de modo dominante, um alcance prático e uma profundidade ideológica que permite estruturar e subordinar as outras culturas. A sociedade de consumo, que a população está submetida na atualidade, demonstra o quão é cultural a prática de consumir e envolve as relações interpessoais.

O consumo, como apresentado até então, é uma prática constante do ser humano, todavia, a partir do momento em que o consumo de bens e serviços se torna extravagante, tal fenômeno pode ser conhecido como consumismo, que parte de características individuais para um atributo de toda sociedade (Bauman, 2008, Giacomini Filho, 2008). Esse excesso de consumo indica uma despreocupação dos indivíduos quanto aos aspectos da coletividade, na medida em que a consequência individualista indica o pensamento alienado quanto à abundância de recursos no meio ambiente.

Tal fato demonstra a necessidade de mudança na maneira como se visualiza o modelo de desenvolvimento atual e, por conseguinte, nas práticas de consumo até então realizadas. Isso pode ser conquistado com a modificação no paradigma de consumo, em que se busca redirecionar a visão do consumo moderno, que se caracteriza pela produção exclusivamente voltada para a venda, no mercado a consumidores, (Slater, 2002) para um pensamento mais holístico das ações desempenhadas (Pnuma, 2001).

Como as práticas de consumo são individuais, percebe-se que cada um possui a condição de escolha sobre suas ações. Cada vez mais, seguindo a ideia de mudança de paradigma e considerando-a viável, Santos, Leite, Tacconi e Alexandre (2008) afirmam que estão surgindo novas preocupações por parte do consumidor, que mudaram o foco individualista de seu consumo para uma visão mais ampla, dando origem ao movimento, na sociedade, por um consumo mais consciente.

Entendendo que de forma alguma o consumir pode deixar de ser praticado pela população, no entanto o consumo consciente se efetiva ao ser levado em consideração os impactos provocados pelo consumo, buscando maximizar os impactos positivos e minimizar os negativos, de acordo com os princípios da sustentabilidade (Instituto Akatu, 2010). Desse modo, torna-se possível perceber que há possibilidade de redirecionamento das características de consumo, considerando a nova ideia emergente de preocupação com a busca do desenvolvimento sustentável.

Com relação à prática do consumo e à forma de desenvolvimento adotada pelas nações, pode-se afirmar que um dos objetivos para o alcance do desenvolvimento sustentável se dá por meio da mudança nos padrões de consumo, ao se perceber a necessidade de "[...] promover padrões de consumo e produção que reduzam as pressões ambientais e atendam às necessidades básicas da humanidade" (Agenda 21, 1992). Partindo desse princípio, torna-se possível a busca pelo consumo sustentável.

Revista de Gestão Social e Ambiental - RGSA, São Paulo, v. 5, n. 2, p.18-33, mai./ago. 2011. 
No debate acerca do consumo, percebe-se a falta de consenso na definição do que vem a ser consumo sustentável. Muitas vezes confundido com o consumo consciente, focado apenas no indivíduo, a prática sustentável do consumo traz a ideia de coletividade em torno desse fenômeno, na medida em que diversos atores sociais interferem em sua efetivação. Nesse caso, torna-se relevante distinguir tais constructos, de forma que se consiga uma melhor compreensão de suas características. Essa confusão abre uma lacuna teórica tratada na discussão desse estudo.

Diante dessas considerações, o consumo sustentável, analogamente ao conceito de desenvolvimento sustentável, pode ser considerado como a prática de consumo que utiliza os recursos naturais para satisfazer as necessidades atuais, sem comprometer as necessidades e aspirações das gerações futuras (Bedante, 2004, Gomes, 2006, Cortez \& Ortigoza, 2007, Costa \& Oliveira, 2009). Assim sendo, o consumo sustentável pode ser definido, segundo Silva (2010, p.8), como "[...] o padrão de consumo resultante das inter-relações entre os atores sociais (GovernoEmpresa-Sociedade) direcionado ao alcance do desenvolvimento sustentável", devendo cada um desses atores assumir papéis e obrigações distintas direcionados ao consumo sustentável.

Desse modo, apesar de se verificar essa existência de preocupações inter e intrageracional com relação à continuidade da prática de consumo, faz-se necessário compreender que, para a efetivação sustentável do consumo, há uma complexidade de relações que permeiam a dinâmica de mercado. Assim sendo, para Portilho (2003), o consumo sustentável surge como uma nova perspectiva em relação às estratégias públicas quanto à esfera do consumo, às novas formas de produção das empresas, bem como às mudanças comportamentais dos indivíduos no mercado. Refere-se a uma nova forma de atuação em todas as esferas, sejam elas econômicas, políticas e sociais, representadas, de forma genérica, respectivamente pela indústria (empresas), pelo governo, bem como pela sociedade, ou seja, por cada indivíduo-cidadão que possua o entendimento quanto a essa prática (Cortez \& Ortigoza, 2007, Panarotto, 2008).

Corroborando com essa ideia, o Programa das Nações Unidas pelo Meio Ambiente - Pnuma (2001) indica a necessidade de mudança nas práticas de consumo, na busca por uma melhor qualidade de vida e que tal fato dar-se-á pela interação e envolvimento entre os atores supracitados, de modo que a coletividade consiga perceber os resultados positivos desse processo dinâmico de influência e relacionamento mútuos (Figura 01), havendo corresponsabilidade, de maneira equiitativa, entre todos esses atores sociais.

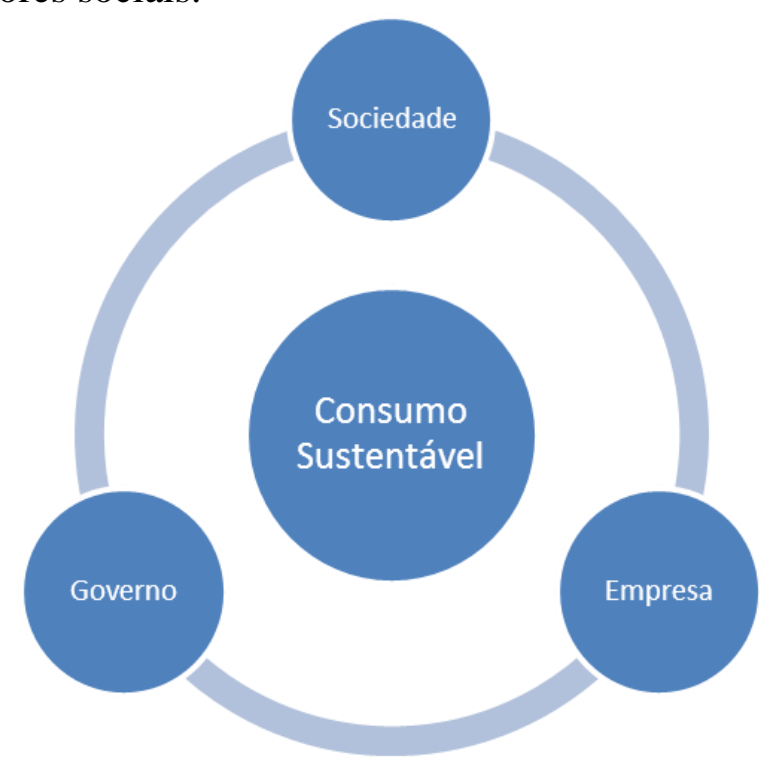

Figura 1: Relações para o consumo sustentável.

Fonte: Elaborado pelos autores

Revista de Gestão Social e Ambiental - RGSA, São Paulo, v. 5, n. 2, p. 18-33, mai./ago. 2011. 
Cada um desses atores deve assumir papéis e obrigações distintas direcionados ao consumo sustentável. O governo desempenha o papel de apoiar pesquisas e contribuir para o estabelecimento de eficiência operacional de produtos e serviços, devendo promover e facilitar, ainda, o desenvolvimento de tecnologias limpas, transferindo-as e adotando-as (Pnuma, 2001). Para Giacomini Filho (2008) a falta de políticas públicas para evitar o excesso no consumo ameaça os avanços legais disponíveis. Assim sendo, indica-se que é imprescindível ao governo assumir o seu papel, de modo que consiga desenvolver e incentivar novas práticas sustentáveis nos outros atores.

O papel da indústria na busca pelo consumo sustentável está, basicamente, relacionado com sua prática de responsabilidade socioambiental, de modo a reestruturar suas ações para a efetivação de uma produção sustentável, capaz de, no exercício desse novo modelo de consumo direcionado ao atendimento de necessidades coletivas, auxiliar a população no fornecimento de produtos e serviços sustentáveis. Uma das propostas principais está na busca por soluções inovadoras direcionadas nesse sentido (Pnuma, 2001). Com essa atitude, consegue-se melhorar a atuação da empresa no mercado, bem como suas relações com os demais atores da sociedade.

Nesse momento, como responsabilidade relacionada ao indivíduo, destaca-se a consciência adquirida em relação à coletividade, assumindo assim a prática do consumo consciente como a ação em que deve desenvolver para que consiga estabelecer seu papel quanto às características sustentáveis. Esse é o desafio fundamental para o movimento dos consumidores (Pnuma, 2001). Desse modo, a consideração dos impactos por ele produzidos no meio ambiente indica sua preocupação com o desenvolvimento sustentável. Diante dessas características, Portilho (2003, p.145) afirma que "[...] a atividade de consumo e o próprio papel do consumidor podem oferecer importantes possibilidades de constituição de sujeitos sociais ativos e de retorno ao cidadão". Entendendo que apesar de, por vezes, ser observado como apenas um participante de um nicho de mercado, o consumidor, como indivíduo-cidadão, representa um elemento de suma importância na busca pelo consumo sustentável.

Considerando as obrigações e os papéis que cada um desses atores sociais desempenha para com o constructo do consumo sustentável, segundo Eddine, Vettorazzi e Freitas (2008), de acordo com essa prática de consciência global, está havendo uma universalização de comportamentos mais éticos e direcionados com as questões envolvendo o meio ambiente. Nesse sentido, todos são afetados pela necessidade de mudança; entretanto, para Tukker et al. (2008), essas mudanças não ocorrem, seguindo a ideia das economias, de forma igual às várias existentes. Os autores afirmam que cada classe econômica específica possui seus desafios a serem atingidos.

Para as economias desenvolvidas, com características de abundância nos recursos financeiros, e com o real consumismo na maioria dos participantes da classe, o desafio encontra-se em fazer mais com menos, mudando o modelo de consumo até então praticado. Nas economias em desenvolvimento, os desafios são totalmente diferentes. A área de atuação que deve ser focalizada no que diz respeito ao processo de construção de estruturas sustentáveis para produção e consumo, com o intuito de melhor adaptar o conjunto de ações previamente imaginadas, direcionadas para o consumo sustentável (Tukker et al., 2008).

A última economia abordada pelos autores, porém não menos importante, envolve a classe econômica com maior quantidade de indivíduos no mundo, qual seja: a base da pirâmide. Até então os objetivos e desafios envolviam ações mais pontuais, mesmo que ainda envolvessem as interrelações entre os atores. Contudo, a ideia inicial para as mudanças nas práticas de consumo na base da pirâmide, envolve a criação de uma base sustentável com crescimento equitativo e erradicação da pobreza, considerando sempre as questões relacionadas com o desenvolvimento sustentável para modificar suas ações.

Assim sendo, apesar de entender que são complexas as relações que devem ser desenvolvidas para que o consumo sustentável possa ser efetivado, pode-se dizer que aquela que apresenta uma das relações imprescindíveis, é a produção-consumo. Levando em consideração o objetivo desse estudo, direcionado ao entendimento das questões de consumo sustentável na base da 
pirâmide, e entendendo-a, segundo Prahalad e Hart (2000), como uma vasta classe emergente de consumo, faz-se necessário reconhecer quais são as principais características desse mercado, buscando destacar os pontos de relevância e, na sequência, reconhecer as ações que podem ser desenvolvidas para que haja o consumo sustentável.

\subsection{Mercado da baixa renda}

A população de renda mais alta sempre foi considerada importante para o comércio e para a indústria, que não viam nos indivíduos das classes C, D e E - a chamada base da pirâmide - o real potencial de consumo que as classes mais abastadas apresentam. Essa valorização das classes A e B sempre foi justificada pela lógica de que, mesmo sendo um mercado restrito a uma pequena parcela da população, vale mais a pena dispor no mercado produtos mais caros, que rendam altas margens de lucro. Contudo, com as mudanças que ocorreram na economia nos últimos anos e no próprio comportamento dos consumidores, essa lógica está mudando gradativamente. Segundo Wright e Cardoso (2000), no Brasil tem-se observado, principalmente após o início do Plano Real, um substancial aumento do poder de compra da população de consumidores de baixa renda.

Entendendo que essa classe emerge como um mercado propício para a atuação profissional, segundo Arruda, Werneck, Rossi e Savaget (2010), isso exige o desenvolvimento de estratégias e atuações diferentes daquelas planejadas para o topo da pirâmide. Esse aspecto é corroborado por Spers et al. (2009a) quando sugerem a necessidade de reestruturação das práticas organizacionais nas diferentes áreas de atuação, o que facilita uma melhor atuação nessa faixa de mercado. Para Prahalad e Hart (2000), os desafios para os gestores que assumem a atuação na base da pirâmide envolvem a criação de mecanismos para estruturação do setor, educação dos consumidores para a escolha por produtos mais sustentáveis, bem como a busca pela redução nos custos, aumentando o sistema de qualidade nas bases comerciais.

De acordo com uma pesquisa da Associação Brasileira de Empresas de Pesquisa - Abep (2010), a população brasileira encontra-se dividida em oito classes, quais sejam: A, com variação para A1 e A2; B, variando para B1 e B2; C, com C1 e C2; D e E. As classes A (A1 e A2) e B (B1 e B2) correspondem, segundo um estudo da Latin Panel (2010), a 23\% da população. O contingente restante abrange as classes $\mathrm{C}(\mathrm{C} 1$ e $\mathrm{C} 2), \mathrm{D}$ e E, que representam $77 \%$ da população brasileira, sendo a classe C responsável por $33 \%$, e as classes D e E por $44 \%$. Segundo esse mesmo estudo, essas classes de baixa renda são responsáveis por $71 \%$ do consumo do país. A distribuição dessa população com relação à renda média por família pode ser visualizada na Tabela 1.

Tabela 1: Distribuição da população brasileira por renda familiar.

\begin{tabular}{|c|c|}
\hline Classe & Renda Média Familiar (Valor Bruto em R\$) - 2008 \\
\hline A1 & $14.366,00$ \\
\hline A2 & $8.099,00$ \\
\hline B1 & $4.558,00$ \\
\hline B2 & $2.327,00$ \\
\hline C1 & $1.391,00$ \\
\hline C2 & 933,00 \\
\hline D & 618,00 \\
\hline E & 403,00 \\
\hline
\end{tabular}

Fonte: Adaptado da Abep (2010)

É possível observar, que o número de pessoas que se localizam nas classes $\mathrm{C}, \mathrm{D}$ e E (base da pirâmide) é muito expressivo e tem, aparentemente, maior potencial de crescimento de demanda do que as classes A e B. Em termos mundiais, 4 bilhões de pessoas ou 2/3 terços da população existente no mundo, encontram-se nestas classes (Prahalad, 2006). Assim, mesmo com seu alto poder aquisitivo, o segmento das classes A e B está muito próximo do ponto de saturação (já 
alcançado para alguns setores) e, com isso, o grande desafio das empresas é procurar uma maneira de conquistar as classes mais baixas.

Contudo, apesar do potencial de mercado existente na base da pirâmide, Prahalad (2006) argumenta que não basta compreender que existe a possibilidade de se explorar esse mercado emergente. $\mathrm{O}$ ideal seria que, ao invés de esperar que os menos favorecidos se transformem em consumidores, por meio do aumento de renda, as empresas deveriam buscar meios para criar esses novos consumidores, ampliando assim, os limites do mercado e vinculando os objetivos das empresas aos da sociedade, de maneira geral.

Dessa forma, segundo Prahalad (2006), é necessário estimular o consumo dessas classes de baixa renda, para que as empresas consigam aproveitar oportunidades, garantir ganhos econômicos, e ainda, possibilitar a inserção social da população, alcançada a partir da elevação do nível de consumo. No entanto, com potencial de consumo significativo, mas certa limitação de renda é evidente que o consumo popular tem características muito próprias, e é necessário entender como esse consumo ocorre, para que não apenas as questões econômicas e sociais sejam alcançadas, mas também o aspecto ambiental, uma vez que a consciência e o comportamento dos consumidores estão continuamente mudando e que é preciso orientá-los para que esses três pilares do desenvolvimento sustentável possam ser garantidos.

Nesse sentido, as empresas precisam definir suas estratégias para aproveitar oportunidades advindas desse mercado, ao mesmo tempo em que devem contribuir para o desenvolvimento social e ambiental da comunidade na qual estejam inseridas. Segundo Ohmae (1998), a estratégia de uma empresa será mais adequada quando possibilitar entender melhor as necessidades dos clientes e criar valor para eles. Nesse contexto, verifica-se que a base da pirâmide, tem forte consciência de marca e é capaz de realizar análises de valor complexas: "[...] pobres querem produtos de alta qualidade a preços baixos, que promovam a sua ascensão social e econômica" (Prahalad, 2006, p.25).

Assim, empresas e sociedade têm ampliado sua compreensão sobre o que, de fato, contribui para o desenvolvimento social. Neste contexto, busca-se combinar melhor a perspectiva das empresas com as demandas sociais e criar um novo patamar no movimento contemporâneo de valorização da sustentabilidade e responsabilidade corporativa. Tal patamar envolve a modificação de algumas realidades, tanto em termos de condições econômicas da população, pelo engajamento social em processos de transformação de condições de vida; quanto com relação às atividades inerentes às empresas, que precisam ser mais bem definidas e customizadas para esse público.

Dessa forma, para lidar com a base da pirâmide, não basta apenas servir um mercado já existente de maneira mais eficiente, mas remodelar processos, rever valores e articular parcerias, para que o consumo possa ser estimulado, mas sem interromper o alcance do desenvolvimento sustentável.

\subsubsection{Massificação sustentável}

Como já mencionado, conforme Prahalad (2006), a base da pirâmide representa um potencial enorme de consumidores, ansiosos para adquirir produtos e se sentirem parte da sociedade, seja por necessidades básicas ou de realização, seja apenas pela autoestima e status. Entretanto, trata-se também de uma população que, em sua maioria, não apresenta preocupação ambiental, nem tampouco com questões de degradação, e pouco compreende as inúmeras consequências que um consumo exacerbado geraria no ambiente.

Portanto, apesar de o incentivo ao consumo ter sido considerado como a solução para o problema da pobreza e para questões sociais, no que diz respeito ao sentir-se parte da sociedade inclusão social - deve-se atentar que, nesse caso, haveria uma intensificação de produção de resíduos e elevação dos níveis de degradação e prejuízos ambientais.

Nesse sentido, Guimarães (2008) criou um conceito denominado massificação sustentável, para descrever o processo de estender as possibilidades de consumo de produtos e serviços para os

Revista de Gestão Social e Ambiental - RGSA, São Paulo, v. 5, n. 2, p.18-33, mai./ago. 2011. 
$86 \%$ da população mundial que está parcial ou quase totalmente excluída (Mahajan e Banga apud Guimarães, 2008), sem, contudo, “[...] comprometer a capacidade das gerações futuras de atender às suas próprias necessidades" (Guimarães, 2008, p. 40).

Assim, a massificação sustentável tem como objetivo garantir a inclusão social da população de baixa renda a partir do consumo, ao mesmo tempo em que busca não prejudicar a satisfação das necessidades das gerações futuras, garantindo, dessa forma, o alcance do desenvolvimento sustentável. Incentiva-se, pois, o consumo da base da pirâmide, de forma sustentável, onde as perspectivas ambiental, social e econômica se encontram integradas.

A partir dessas considerações, ao identificar a necessidade de mudança no paradigma desenvolvimentista, bem como no paradigma de consumo praticado, é de extrema relevância que se observem as características que permeiam essa propensa mudança. Optou-se por focalizar a base da pirâmide, uma vez que demonstra potencial de crescimento a curto prazo. A efetivação de um consumo sustentável nessa classe econômica surge como alternativa possível, na medida em que é necessária a definição e criação desses padrões e dessa cultura de consumo preocupadas com o desenvolvimento sustentável.

\section{CONSUMO SUSTENTÁ VEL NA BASE DA PIRÂMIDE}

Os estudos que vêm sendo realizados para a compreensão e o desenvolvimento da classe econômica de baixa renda, a chamada base da pirâmide, têm se preocupado com a busca por alternativas de inserção dessa faixa populacional, muitas vezes marginalizada, na dinâmica de mercado, ao compreender que englobam grande parte da população mundial atualmente. Todavia, as discussões que envolvem essa classe, com a intenção de inserir o social - umas das dimensões do desenvolvimento sustentável - na criação desse mercado emergente, às vezes, pode acarretar uma desarmonia quanto a essas dimensões, ao focalizar uma ou outra mais especificamente.

Corroborando com o pensamento, Arruda et al. (2010) trazem a ideia de que esse mercado consumidor, de fato, ainda não está posto, o que indica a necessidade de criação de uma nova lógica de desenvolvimento direcionado a essa população, no sentido de surgir um novo mercado de consumo. Mas, por que não criar esse mercado seguindo os princípios do desenvolvimento sustentável? Por que não estimular a prática do consumo sustentável visualizando a inserção social na dinâmica de mercado, ampliando os padrões de retorno para a empresa e, mais ainda, como pouco se vem focando até então, mantendo a preocupação com os impactos que esse novo mercado consumidor irá causar sobre o meio ambiente? Tais questionamentos e muitos outros estimulam a pesquisa nessa área, tendo em vista a gama de possibilidades que envolvem tal aspecto.

Nesta perspectiva, buscando entender e visualizar a criação de um novo paradigma de consumo junto à base da pirâmide em uma dada localidade, percebe-se a possibilidade de criação de uma nova cultura de consumo, cujo maior objetivo nas práticas consumidoras seja a preocupação com a coletividade. Ao observar que o foco dos estudos até então desenvolvidos e reconhecidos na literatura nessa área, estão direcionados à busca pela inserção social e ao retorno econômico empresarial, é necessário uma maior visualização para as questões ambientais, que dão o suporte para o desenvolvimento de qualquer outra atividade.

Desse modo, o consumo sustentável, que defende atuação e inter-relação de atores sociais (governo, empresa e sociedade), sugere a incorporação dessa outra dimensão (ambiental) na medida em que seus preceitos estão voltados ao atendimento das expectativas e princípios do desenvolvimento sustentável, de maneira que cada um desses atores sejam corresponsáveis por uma atuação mais pró-ativa e preocupada com as questões de coletividade. Para melhor entender esse contexto de consumo sustentável na base da pirâmide, faz-se necessário retomar aspectos considerados pertinentes.

Como a literatura assume que o papel principal, na busca pela inserção da base da pirâmide no mercado - até pelo caráter lucrativo que pode vir a proporcionar - está direcionado para a

Revista de Gestão Social e Ambiental - RGSA, São Paulo, v. 5, n. 2, p. 18-33, mai./ago. 2011. 
empresa, torna-se relevante entender a dinâmica da classe sobre esse prisma. Segundo Spers e Wrigth (2006), as empresas que buscam atuar no segmento de bens populares, devem procurar vantagem competitiva em custos para haver a prática de preços mais baixos, com produtos menos sofisticados, mas que satisfaçam as necessidades do consumidor que prioriza a questão do preço.

De forma complementar, Spers, Wrigth e Castro (2008) indicam que a empresa que opta por focar a base da pirâmide, tem como um dos fatores intrínsecos a essa ação, a capacidade de transformação que o produto pode gerar. A partir dessas considerações, percebe-se que há uma preocupação intensificada com os aspectos sociais e econômicos - que nesse caso, atende não apenas a empresa, como também a dinâmica econômica de forma geral - mas que é necessário um direcionamento, uma maior atenção para com os aspectos ambientais, de forma que estes não fiquem a mercê de outras questões organizacionais.

As empresas necessitam, pois, definir em que zonas da pirâmide pretendem atuar (Giovinazzo \& Wright, 2004), e o mercado de baixa renda, que engloba as classes C, D e E, e apresenta taxas de crescimento maiores do que a média do topo (Arruda et al., 2010), pode se tornar a opção correta de escolha. Tal fato pode ocorrer por meio da massificação sustentável, que busca atender essa faixa econômica com a preocupação necessária em relação ao desenvolvimento sustentável. Todavia, esse fenômeno pode não observar as consequências resultantes dessa massificação, o que para Hart (2006, p.154) pode ser minimizado com a "[...] avaliação do efeito do sistema empresarial completo sobre as comunidades e os ambientes nos quais ele é introduzido".

Para Prahalad (2010, p.28), “[...] suprir os consumidores da base da pirâmide exigirá inventividade em tecnologia, produtos/serviços e modelos de negócios". Desse modo, as empresas devem compreender o seu papel de transformadora quanto às questões sustentáveis, na medida em que se preocupam em ofertar produtos/serviços mais bem direcionados nesse sentido. Como no Brasil predomina essa faixa econômica em toda a população, o mercado necessita reconhecer as características mais pertinentes para uma melhor atuação nessa classe, compreendendo seu comportamento e as práticas de consumo desenvolvidas (Guimarães, 2008).

Em pesquisa recente para o entendimento das necessidades envolvendo a base da pirâmide, Subramahnyan e Gomez-Arias (2008) apresentaram as seguintes categorias de consumo, consideradas como essenciais: alimentação, energia, moradia, transporte, saúde, água, informação e tecnologia. Tais setores podem ser o ponto de partida para a mudança e inserção da prática sustentável, no sentido de reestruturar os padrões de consumo e influenciar o desenvolvimento de uma preocupação e atuação junto a um consumo sustentável.

Para Spers et al. (2009a), na busca por atender a essa faixa da economia, de realizar a satisfação de suas necessidades, existe uma preocupação, por parte das empresas, em adaptar os produtos/serviços de forma que se tornem mais eficientes e adequados para essa parte da população. Tal fato pode ser observado, por exemplo, no setor de construção - categoria moradia anteriormente apresentada - no qual, segundo Carvalho, Guimarães e Castillo (2008), é necessário o desenvolvimento de projetos sustentáveis aplicáveis à base da pirâmide, com processos e tecnologias reduzindo os impactos gerados pela indústria, fato este até então observado apenas no topo da pirâmide.

$\mathrm{Na}$ busca pelo atendimento dessas necessidades, seguindo os princípios do desenvolvimento sustentável, e na construção de um paradigma de consumo sustentável na base da pirâmide, é necessário a existência de uma inter-relação entre os atores sociais envolvidos, com o intuito de melhorar o desempenho no mercado. Corroborando com a ideia, Prahalad e Hart (2000) indicam que na atuação junto a base da pirâmide, as empresas necessitam interagir com outros atores sociais como ONGs, instituições financeiras, autoridades governamentais, entre outros atores, com o intuito de criar um poder de compra, moldar as aspirações, melhorar o acesso para essa população, direcionando, dessa maneira, o desenvolvimento de mercados saudáveis.

Desse modo, identificando essa necessidade de corresponsabilidade de cada ator na busca pela efetivação de um consumo sustentável, o papel da empresa está na realização de inovações em

Revista de Gestão Social e Ambiental - RGSA, São Paulo, v. 5, n. 2, p.18-33, mai./ago. 2011. 
suas práticas organizacionais que facilitem tal objetivo. Essa característica é entendida como um imperativo para capturar a oportunidade de atuação na base da pirâmide (Prahalad \& Hart, 2000). Corroborando com esses autores, Arruda et al. (2010) afirmam que as inovações destinadas a essa faixa econômica representam uma contribuição mais efetiva e profunda para o desenvolvimento social. Dessa forma, Kiperstok et al. (2002, p. 9) afirmam que a inovação é orientada pelo mercado, pela regulamentação, pelo padrão dos produtos e pelos processos tecnológicos utilizados, o que força a empresa a inovar de acordo com outros aspectos, além do econômico.

Com relação ao governo, para que essa preocupação com o consumo sustentável possa vir a se tornar rotineira nas atividades empresariais e da sociedade, é imprescindível que também assuma o papel de corresponsável, entendendo que pela implantação, por exemplo, de políticas públicas e programas educacionais, ele consegue desenvolver ou incentivar novas práticas sustentáveis nos outros atores. Assim, suas ações devem estar direcionadas a incentivar a inserção empresarial na base da pirâmide, contudo, coordenando para que essas empresas se guiem pelos princípios pertinentes ao consumo sustentável, à luz das características do desenvolvimento sustentável.

Por fim, o outro ator social que assume papel de responsabilidade no alcance do consumo sustentável é o indivíduo. Considerando o potencial da base da pirâmide, que se relaciona com a possibilidade de consumo que esse segmento possui, cada indivíduo deve assumir que apresenta a opção de escolha em relação a algumas situações, e que no momento de uma compra, por exemplo, sua atitude deve ser direcionada para produtos ou serviços sustentáveis. Tal ação indica a consciência que possui sobre algumas características. Nesse contexto, utiliza-se da capacidade de discernimento sobre diferentes alternativas possíveis.

Diante dessas considerações, a partir do momento em que cada um desses atores sociais desempenhar sua responsabilidade, pode-se verificar a proximidade que há do alcance do consumo sustentável, na medida em que essas relações sugerem uma maior preocupação com questões globais, relacionadas ao desenvolvimento sustentável, com todos os atores assumindo vantagens positivas. Ao observar tais aspectos, torna-se relevante a disseminação dessas características com o intuito de incutir a ideia de responsabilidade que cada um possui em relação ao outro ator.

\section{CONSIDERAÇÕES FINAIS}

O entendimento da necessidade de mudança no modelo desenvolvimentista praticado, bem como do redirecionamento do pensamento individualista para um mais coletivo, direciona a percepção de que o desenvolvimento sustentável apresenta-se como a melhor alternativa nesse sentido. Apesar de uma ideia mais holística, vale salientar que para o alcance da forma de desenvolvimento proposta é necessário que haja a inter-relação entre os atores: governo, empresa e sociedade.

A partir do momento em que cada um desses atores assume sua corresponsabilidade na busca pela modificação na visão de modelo de desenvolvimento, faz-se necessário um redirecionamento quanto as questões de consumo, surgindo, assim, o consumo sustentável. Por ser visualizado nas várias faixas econômicas da sociedade, optou-se por estudar a base da pirâmide pelo seu potencial de crescimento.

Com objetivo de compreender como o consumo sustentável poderia ser efetivado na base da pirâmide, buscou-se, por meio deste estudo, inter-relacionar as ideias de desenvolvimento dessa faixa econômica com os princípios do desenvolvimento sustentável. Foram apresentadas ações a serem realizadas, indicando que cada ator social possui o seu papel nesse sentido. É fato que ainda está incipiente a discussão ampla nessa área, todavia percebe-se a possibilidade de efetivação da ideia na base da pirâmide ao retomar a visão de Arruda et al. (2010) que indicam a necessidade de criação e organização dessa população.

Seguindo esse pensamento, ao direcionar suas atividades com o intuito de melhorar o desempenho da economia, incluir socialmente os indivíduos e preocupar-se com o ambiente, torna-

Revista de Gestão Social e Ambiental - RGSA, São Paulo, v. 5, n. 2, p. 18-33, mai./ago. 2011. 
se possível a melhoria nas condições de vida dessa população, muitas vezes marginalizada. Todas essas ações estariam permeadas pela ideia de desenvolvimento sustentável visando as questões coletivas.

Nesse contexto, percebe-se a necessidade de pesquisas nessa área do conhecimento ao entender que a inclusão da base da pirâmide é uma realidade próxima na prática de desenvolvimento atual, mas que necessita de uma visualização mais detalhada sobre essa inserção. Trabalhos podem ser desenvolvidos, de forma mais direcionada, para cada um desses atores apresentados, ou eles em conjunto, de modo que se consiga identificar soluções pragmáticas para a efetivação do consumo sustentável nessa faixa da população.

Percebe-se ainda, a necessidade de se estudar as outras classes econômicas, demonstradas por Tukker et al. (2008), uma vez que, de forma mais impactante, o topo da pirâmide de economias em desenvolvimento possuem um consumo indiscriminado dos recursos naturais, com a ideia, ainda de abundância, desses recursos o que não ocorre mais. Como também, das economias em desenvolvimento, principalmente, em países emergentes, salientando que em um mesmo país todas essas economias estão presentes e podem ser estudadas complementarmente.

\section{REFERÊNCIAS}

Abep - Associação Brasileira de Empresas de Pesquisa. (2010). Critério de classificação econômica Brasil. Recuperado em nov. 2010, de: <http://www.abep.org/novo/Content.aspx?ContentID=301>.

Agenda 21. (1992) Capítulo 4: mudança dos padrões de consumo. Conferência das Nações Unidas sobre Meio Ambiente e Desenvolvimento.

Arruda, C., Werneck, N.; Rossi, A., Savaget, P. (2010). Oportunidades e desafios de inovar para a base da pirâmide. Revista da Fundação Dom Cabral, n. 11.

Barbieri, J.C., Cajazeira, J.E.R. (2009). Responsabilidade social empresarial e empresa sustentável. São Paulo: Saraiva.

Baudrillard, J. (2007). A sociedade de consumo. Lisboa: Arte \& Comunicação.

Bauman, Z. (2008). Vida para o consumo: a transformação de pessoas em mercadorias. Rio de Janeiro: Jorge Zahar Ed..

Bedante, G.N. (2004). A influência da consciência ambiental e das atitudes em relação ao consumo sustentável na intenção de compra de produtos ecologicamente embalados. 2004. $159 \mathrm{f}$. Dissertação (Mestrado em Administração) - Programa de Pós-Graduação em Administração. Universidade Federal do Rio Grande do Sul, Porto Alegre, Brasil.

Borger, F.G. Responsabilidade corporativa: a dimensão ética, social e ambiental na gestão das organizações. In: Vilela Júnior, A., Demajorovic, J. (2006). Modelos e ferramentas de gestão ambiental. p. 13-40. São Paulo: Senac.

Buarque, S.C. (2008). Construindo o desenvolvimento local sustentável. (4 ed.) Rio de Janeiro: Garamond. 
Carvalho, N.C., Guimarães, M.G., Castillo, L.A.G. (2008). Desenvolvimento de alternativas sustentáveis para habitação de baixa renda. In Anais... Congresso Brasileiro de Pesquisa e Desenvolvimento em Design, 8, São Paulo, Brasil.

Casagrande Jr, E.F. (2003). Inovação tecnológica e sustentabilidade: integrando as partes para proteger o todo. Palestra do Seminário de Tecnologia - PPGTE - CEFET-PR: Curitiba.

Cortez, A.T.C., Ortigoza, S.A.G. (2007). Consumo sustentável: conflitos entre necessidades $e$ desperdício. São Paulo: Editora UNESP.

Costa, F.J., Oliveira, L.G.L. (2009). Produção e consumo sustentável: um estudo de caso. In: Anais... Simpósio de Administração da Produção, Logística e Operações Internacionais SIMPOI, 7.

Eddine, S.C., Vettorazzi, K.M., Freitas, V.P. (2008). Consumo e sustentabilidade: desafios para uma nova atitude ecológica. In Anais... Congresso Nacional do CONPEDI, 7. Brasília, Brasil.

Giacomini Filho, G. (2008). Meio ambiente \& consumismo. São Paulo: Editora Senac São Paulo.

Giovinazzo, R.A., Wright, J.T.C. (2004). O mercado e o desempenho das empresas focadas em bens populares no Brasil. In Anais... SemeAd., 7 São Paulo: USP.

Gomes, D.V. (jun.2006) Educação para o consumo ético e sustentável. Revista eletrônica Mestrado em Educação Ambiental, 16.

. (2007). A importância do exercício da cidadania na efetivação do direito fundamental ao meio ambiente ecologicamente equilibrado. 120 p. Dissertação (Mestrado em Direito) Programa de Pós-Graduação em Direito. Universidade de Caxias do Sul, RS, Brasil.

Guimarães, L.F. (2008). Massificação sustentável: uma contribuição para o processo de inovação sustentável em mercados emergentes. 123p. Dissertação (Mestrado), Universidade de São Paulo, SP, Brasil.

Hart, S. (2006). O capitalismo na encruzilhada. Porto Alegre: Bookman.

Instituto Akatu para o consumo consciente. (2010). O que é consumo consciente? Recuperado em jul.2010, de <http://www.akatu.org.br/consumo_consciente/oque>.

Kiperstok, A., Costa, D.P., Andrade, J.C., Agra Filho, S., Figueroa, E. (nov. - dez 2002). Inovação como requisito do desenvolvimento sustentável. REAd-Edição especial, 30(6).

Mccracken, G. (2003). Cultura e consumo: novas abordagens ao caráter simbólico dos bens e das atividades de consumo. Rio de Janeiro: MAUAD.

Ohmae, K. (mai/jun.1998). Os novos limites da empresa. Revista HSM Management, São Paulo, Editora Savana, 22-26.

Panarotto, C. (2008). O meio ambiente e o consumo sustentável: alguns hábitos que podem fazer a diferença. Revista das relações de consumo. Caxias do Sul. 
Pnuma - Programa das Nações Unidas para o Meio Ambiente. (2001). Rumo ao consumo sustentável na América latina e caribe. Workshop sobre consumo sustentável na América Latina e Caribe. São Paulo.

Portilho, M. de F. F. (2003). O discurso internacional sobre consumo sustentável: possibilidades de politização e ambientalização da esfera privada. 170 p. Tese (Doutorado em Ciências Sociais) Programa de Pós-Graduação em Sociologia. Universidade Estadual de Campinas, São Paulo, Brasil.

Prahalad, C. K., Hart, S. (2000). Raising the bottom of pyramid: strategies for sustainable growth. Recuperado em jul.2010, de: www.ima.kth.se/utb/MJ1501/pdf/prahalad.pdf.

Prahalad, C. K. (2006). A riqueza na base da pirâmide: como erradicar a pobreza com o lucro. Porto Alegre: Bookman.

A riqueza na base da pirâmide: como erradicar a pobreza com o lucro. (2010). Porto Alegre, Bookman.

Sachs, I. (2007). Rumo à ecossocioeconomia: teoria e prática do desenvolvimento. São Paulo: Cortez.

. (2008). Caminhos para o desenvolvimento sustentável. Rio de Janeiro: Garamond.

Santos, T.C., Leite, A.P.R., Toni, M.F.F.S., Alexandre, M.L. (2008). Movimento do consumo consciente: do cidadão consumidor ao consumidor cidadão? In Anais... Encontro de Administração Pública e Governança - EnAPG. Salvador, BA, Brasil.

Schumacher, E. F. (2001). Lo pequeno es hermoso. Espana: Tursen S.A.

Silva, M.E. (2010) Consumo sustentável: Em busca de um constructo. In Anais... Encontro Internacional sobre Gestão Empresarial e Meio Ambiente - ENGEMA, 7. São Paulo: FEA-USP.

Slater, D. (2002). Cultura do consumo \& modernidade. São Paulo: Nobel.

Spers, R.G., Wright, J.T.C. (2006). Mercado de bens populares no Brasil: desempenho e estratégia das empresas. In Anais... EnANPAD, 30. Salvador, BA, Brasil.

Castro, H.S.F. (2008). Mapeamento do potencial de consumo da população de baixa renda no Brasil: uma análise do setor de crédito e de bens de consumo. In Anais... XI SemAd, 11. USP, São Paulo, Brasil.

, Carneiro, C.C., Julio Filho, O., Abreu Junior, P.A., Mateev, Z., Wright, J.T. C. (2009a). Proposição e teste de um modelo de turismo para a população de baixa renda na cidade de São Paulo. Revista Eletrônica de Ciência Administrativa - RECADM, 8(1), 18-30.

, Wright, J.T.C., Cheruti, A., Pinto, B.J. V., Fonseca, G., Lima, M.M. (2009b). Desafios e oportunidades no setor de cartão de crédito: proposição de estratégias para o mercado popular. Revista de Gestão da USP, 15(4), 19-35.

Subramahnyan, S., Gomez-Arias, T. (2008). Integrated approach to understanding consumer behavior at bottom of pymarid. Journal of Consumer Marketing, 25(7). 
Tukker, A., Emmert, S., Charter, M., Vezzoli, C., Sto, E., Andersen, M.M., Geerken, T., Tischner, U., Lahlou, S. (2008). Fostering change of sustainable consumptiom and production: an evidence based view. Journal of cleaner production, 16.

Wced - World Comission on Environment and Development. (1987). Report Our commom future. Genebra. Recuperado em jul.2010, de: <http://www.un-documents.net/wced-ocf.htm.>.

Wright, J.T.C., Cardoso, M.V. (2000). Oportunidades estratégicas en el segmento de baja renta em América del Sur. In: Congresso Latino-Americano de Estratégia, 2000, 7. Puebla, México. Anais do Congresso Latino-americano de Estratégia, 7 Puebla, México. 
Data do recebimento do artigo: 21/10/2010

Data do aceite de publicação: 15/07/2011 